\title{
ANÁLISE DAS DEMONSTRAÇÕES CONTÁBEIS DO ESTADO DE GOIÁS: UMA FERRAMENTA PARA AUXILIAR A TRANSPARÊNCIA PÚBLICA
}

Ricardo Sartori Cella1, Michele Rílany Rodrigues Machado².

${ }^{1}$ Mestrando do Programa de Pós-Graduação em Ciências Contábeis da Universidade Federal de Goiás - UFG. Goiânia, Brasil.

(ricardosartoricella@gmail.com)

2 Professora Doutora da Faculdade de Administração, Ciências Contábeis e

Economia da Universidade Federal de Goiás - FACE/UFG. Goiânia, Brasil.

\section{Recebido em: 08/04/2017 - Aprovado em: 10/06/2017 - Publicado em: 20/06/2017 DOI: 10.18677/EnciBio_2017A143}

\begin{abstract}
RESUMO
A análise das demonstrações contábeis públicas é uma técnica contábil que permite compreender a situação econômica e financeira do ente governamental, bem como analisar os reflexos das decisões dos gestores ante o patrimônio público ao longo dos anos. Considerando que os estudos na área de análise de balanços públicos são escassos, e os relatórios apresentados pela administração pública possuem um caráter expositivo, revela-se a necessidade de realizar novas pesquisas nesta temática. O objetivo deste estudo foi analisar as demonstrações contábeis do Estado de Goiás, no período de 2006 a 2013, através do uso de índices financeiros, traçando um panorama dos seus valores ao longo do tempo. A metodologia consistiu em uma pesquisa documental nos Balanços Patrimoniais, Financeiros e demais demonstrativos exigidos pela Lei de Responsabilidade Fiscal do Governo do Estado de Goiás, para subsidiar a análise dos indicadores financeiros do período de 2006 a 2013. O estudo permitiu concluir que o ano de 2013 correspondeu à melhor situação financeira desde 2006 e a dívida consolidada é crescente ao longo dos anos.
\end{abstract}

PALAVRAS-CHAVE: Análise, Demonstrações Contábeis, Estado de Goiás, transparência.

\section{GOIAS FINANCIAL STATEMENTS ANALYSIS: A TOOL FOR PUBLIC TRANSPARENCY}

\begin{abstract}
Financial statements analysis is an accountant technique that allows to comprehend economical and financial situation from the Government, as well as to analyze the reflexes of the managers' decisions against the public patrimony over the years. Considering the lack of studies upon public balance sheets, the presented reports showed by public administration have a expository character, reveals the need to emphasize researches in this subject. This study had as objective to do a financial statements analysis from Goias State, from 2006 to 2013, through the use of financial indexes, outlining their values over time. Methodology consisted on a documentary research on Balance Sheets and other statements required by the Law
\end{abstract}


of Fiscal Responsibility of the Government of the State of Goiás, to subsidize the analysis of the financial indicators of the period from 2006 to 2013 . The study allowed to conclude that 2013 corresponded to the best financial situation since 2006 and the long-term public debt is increasing through the years.

KEYWORDS: Analysis, Financial Statements Reports, Transparency, Goias State.

\section{INTRODUÇÃO}

A análise das demonstrações contábeis permite realizar comparações com tendências regionais ou dos segmentos onde a empresa está inserida, traçar perspectivas futuras da rentabilidade ou continuidade dos negócios, decidir acerca de investimentos e financiamentos, implementar mudanças práticas quando o cenário atual ou projetado não corresponda às estratégias adotadas (SILVA, 2014).

Segundo COELHO \& QUINTANA (2008), os gestores públicos, no exercício de sua função de administrar os escassos recursos financeiros disponíveis para prover serviços de qualidade à população, necessitam de instrumentos capazes de subsidiar a tomada de decisões. Nesse sentido, a análise das demonstrações contábeis revela-se uma importante ferramenta de gestão pública, pois possibilita a visão do patrimônio público em três tempos: passado (histórico), presente (a atual gestão) e futuro (projeção).

Para ANDRADE (2013), a tomada de decisão, quando subsidiada por informações confiáveis e suportada pela análise dos demonstrativos contábeis, permite ao gestor público um maior acerto na tomada de decisões, contribuindo para a melhoria da eficiência, da economicidade e equilíbrio dos gastos públicos. SILVA et al., (2013), apontaram que a acessibilidade aos resultados presentes nos Balanços Públicos contribui para o controle social e a formação de opinião e, com isso, beneficia o cidadão, que passa a conhecer melhor as ações do governante e passa a exercer com propriedade a cidadania, fazendo uma melhor escolha do seu representante através do voto.

O Governo do Estado de Goiás apresenta anualmente, no Portal Transparência, o Relatório da Gestão Financeira como parte integrante do Balanço Geral do Estado. Entretanto, a abordagem é de caráter meramente expositiva dos valores nominais e percentuais da gestão orçamentária financeira e patrimonial, com apresentação de alguns quocientes e tabelas do exercício vigente, mas que deixa de trazer a público a análise descritiva da análise dos demonstrativos em linguagem acessível ao cidadão comum.

Especialmente no Estado de Goiás, o estudo na área de Balanços Públicos ainda é incipiente no meio científico. Relativamente aos demonstrativos contábeis do Estado, as análises ficam restritas aos órgãos de Controle Externo, em específico, o Tribunal de Contas do Estado de Goiás, que se resume a um trabalho técnico. No que se refere especificamente aos indicadores de análise de índices públicos, previstos em lei, são pouco explorados nas referências bibliográficas. ANDRADE (2013) destacou que há escassez de pesquisas acerca da temática contábil de análise de balanços das instituições públicas, nas quais estão incluídas também as autarquias e fundações. Por essas razões, justifica-se a presente pesquisa.

O objetivo deste estudo foi analisar as demonstrações contábeis do Estado de Goiás, no período de 2006 a 2013, através do uso de índices financeiros, traçando um panorama dos seus valores ao longo do tempo. 


\section{MATERIAL E MÉTODOS}

O presente estudo consistiu em uma pesquisa documental nas Demonstrações Contábeis Aplicadas ao Setor Público do Governo do Estado de Goiás, para subsidiar a análise dos indicadores financeiros do período de 2006 a 2013. Nesta pesquisa, para fins de análise das demonstrações contábeis foram objeto de estudo os seguintes demonstrativos contábeis (BRASIL, 1964; BRASIL, 2000):

i. Balanço Patrimonial (Lei 4.320/64, Anexo 14);

ii. Balanço Financeiro (Lei 4.320/64, Anexo 13);

iii. Demonstrativo da Dívida Flutuante (Lei 4.320/64, Anexo 17);

iv. Comparativo da Despesa Orçada, Autorizada e Realizada segundo as Categorias Econômicas e Elementos de Despesas (Lei 4.320/64, Anexo 2);

v. Demonstrativo da Dívida Consolidada Líquida (RGF - Anexo II c/c LRF, art. 55, Inciso I, alínea "b");

vi. Demonstrativo da Receita Corrente Líquida (RREO - Anexo III c/c LRF, art. 53, Inciso I).

A análise limitou-se ao período de 2006 a 2013 em razão de serem os exercícios para os quais a Secretaria da Fazenda do Estado de Goiás disponibilizou os Balanços Gerais em seu endereço eletrônico 'http://www.sefaz.go.gov.br/'.

A partir dos dados brutos obtidos através da observação das Demonstrações Contábeis, as informações foram extraídas e tabuladas em planilhas eletrônicas para poder-se apurar os quocientes de análise de balanços, a evolução dos itens patrimoniais ao longo do período de estudo, razões de proporcionalidade, bem como elaborar gráficos que evidenciassem curvas de tendência e variações comparativas dos elementos. Nesse ponto, utilizou-se da técnica da pesquisa descritiva, em razão da observação, registro, análise e correlação dos fatos ao longo do tempo, porém sem manipulá-los (CERVO, 2007).

Utilizou-se da técnica de análise horizontal ou de evolução para os elementos do Ativo Disponível, Ativo Financeiro, Passivo Financeiro, Receitas, Dívida Flutuante, Dívida Fundada, e Despesa Realizada. A análise vertical foi considerada em caráter complementar para aprofundar o estudo das Receitas e da Dívida Flutuante. No que se refere a liquidez corrente e imediata, adotou-se como critério a análise por índices ou quocientes. Para cálculo dos índices de liquidez corrente (LC) adotou-se a equação 1 e para o índice de liquidez imediata (LI) a equação 2, ambas adaptadas de SOARES et al. (2011):

$$
\begin{gathered}
\mathrm{LC}=\text { Ativo Financeiro / Passivo Financeiro } \\
\mathrm{LI}=(\text { Disponibilidade }+ \text { Recursos Vinculados }) / \text { Passivo Financeiro }
\end{gathered}
$$

Segundo ANDRADE (2013), o índice de liquidez corrente evidencia quanto o Ente Público possui de disponibilidade e créditos para cada unidade de obrigações exigíveis e a liquidez imediata demonstra quanto o ente público possui de disponibilidade de alta liquidez para cada unidade de obrigação exigível no passivo financeiro. Como limitação, neste estudo não foram considerados os efeitos da inflação ao longo do período no que se refere a atualização dos valores originários, restringindo-se à comparação dos dados brutos originários dos demonstrativos. 


\section{RESULTADOS E DISCUSSÃO}

A análise e interpretação das Demonstrações Contábeis Públicas do Estado de Goiás foram efetuadas através do estudo das demonstrações e resultados das contas dos órgãos da Administração Direta, das Autarquias Fundações, Fundos Especiais e Estatais Dependentes sob o regime da Lei Federal n. 4.320/64. Primeiramente, destaca-se que os demonstrativos públicos disponibilizados no endereço eletrônico da Secretaria da Fazenda não são acompanhados de notas explicativas e relatórios de divulgação e apresentação, demonstrando a necessidade de aprimoramento do processo de transparência pública e divulgação das demonstrações contábeis públicas.

$\mathrm{Na}$ Tabela 1, a seguir, demonstra-se o quadro evolutivo da situação financeira do Estado de Goiás com ênfase na variação dos valores nominais monetários do Ativo Disponível, Ativo Financeiro e Passivo Financeiro, componentes básicos para fins de apuração dos índices de liquidez:

\begin{tabular}{|c|c|c|c|c|c|c|}
\hline Ano & Ativo Disponível & AH AD & Ativo Financeiro & AH AF & Passivo Financeiro & AH PF \\
\hline 2006 & $852.422 .600,92$ & - & $1.832 .983 .936,25$ & - & $2.020 .647 .692,84$ & - \\
\hline 2007 & $1.235 .325 .058,41$ & $144,92 \%$ & $2.226 .799 .287,01$ & $121,48 \%$ & $2.441 .391 .656,85$ & $120,82 \%$ \\
\hline 2008 & $1.509 .637 .224,19$ & $122,21 \%$ & $2.550 .512 .915,56$ & $114,54 \%$ & 2.427.908.746,99 & $99,45 \%$ \\
\hline 2009 & $1.671 .208 .034,44$ & $110,70 \%$ & $2.785 .487 .924,33$ & $109,21 \%$ & $2.341 .873 .381,06$ & $96,46 \%$ \\
\hline 2010 & $1.233 .123 .654,53$ & $73,79 \%$ & $2.445 .843 .558,13$ & $87,81 \%$ & $2.436 .886 .004,40$ & $104,06 \%$ \\
\hline 2011 & $2.711 .626 .216,06$ & $219,90 \%$ & $3.005 .598 .024,73$ & $122,89 \%$ & 2.733.798.429,99 & $112,18 \%$ \\
\hline 2012 & $3.212 .916 .410,21$ & $118,49 \%$ & $3.378 .418 .103,05$ & $112,40 \%$ & $3.306 .729 .094,49$ & $120,96 \%$ \\
\hline 2013 & 3.323.234.382,04 & $103,43 \%$ & 3.517.752.725,27 & $104,12 \%$ & 3.068.673.025,98 & $92,80 \%$ \\
\hline
\end{tabular}

AH AD: Análise Horizontal do Ativo Disponível;

AH AF: Análise Horizontal do Ativo Financeiro;

AH PF: Análise Horizontal do Passivo Financeiro

Fonte: Goiás, Balanço Patrimonial (Anos 2006, 2007, 2008, 2009, 2010, 2011, 2012, 2013).

De acordo com a Tabela 1, percebe-se que os maiores crescimentos monetários dos itens patrimoniais ocorreram em 2011 para o Ativo Disponível (219,90\%), também em 2011 para o Ativo Financeiro (122,89\%) e em 2012 para o Passivo Financeiro (120,96\%). Por sua vez, os maiores decréscimos correspondem aos anos de 2010 para o Ativo Disponível (73,79\%), de 2010 para o Ativo Financeiro $(87,81 \%)$ e de 2013 para o Passivo Financeiro (92,80\%). Note-se que apenas nos anos de 2010 e 2012 o crescimento do Passivo Financeiro superou o do Ativo Financeiro, influenciando negativamente a situação líquida dos períodos.

De posse dos valores nominais monetários do Ativo Disponível, Ativo Financeiro e Passivo Financeiro é possível calcular os índices de liquidez corrente e imediata. Também é possível comparar a variação do Ativo Financeiro em relação ao Passivo Financeiro e analisar, por exemplo, se o Estado de Goiás possui recursos suficientes para o pagamento de suas dívidas de curto prazo (Figura 1 - A e B). 


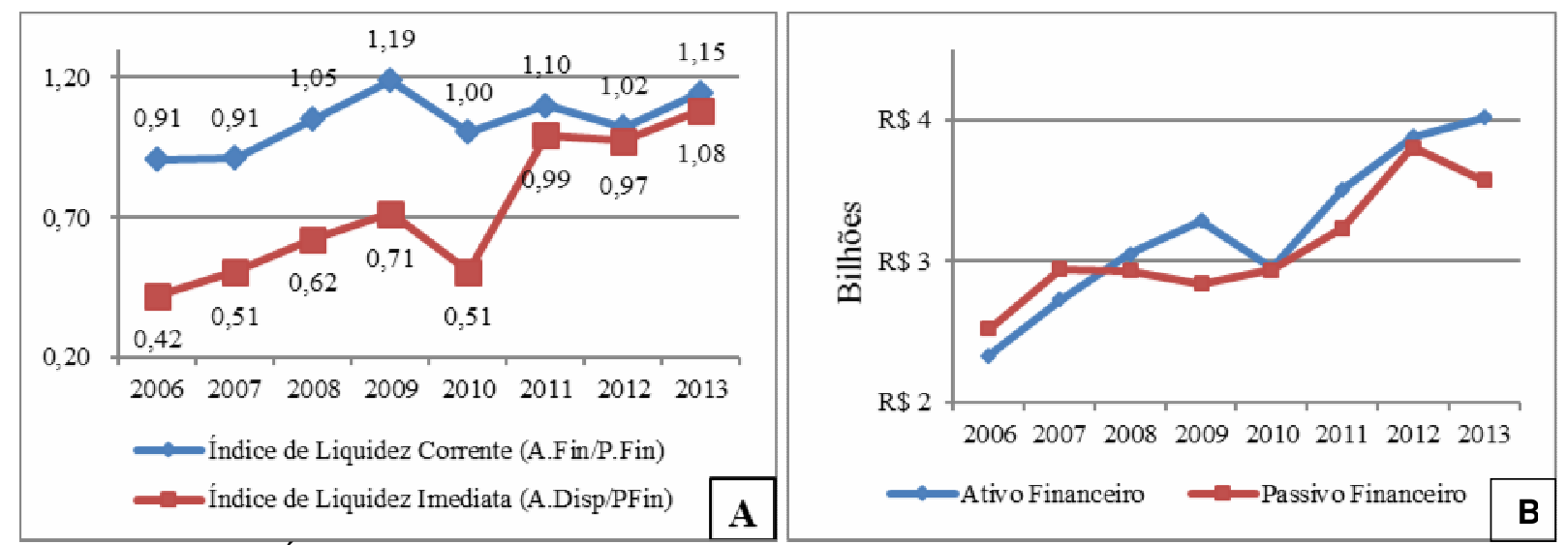

FIGURA 1 - A) Índices de Liquidez; B) Comparativo do Ativo Financeiro com o Passivo Financeiro Fonte: Goiás, Balanço Patrimonial (Anos 2006, 2007, 2008, 2009, 2010, 2011, 2012, 2013).

De acordo com a Figura 1-A é possível perceber que os resultados obtidos através do quociente de liquidez corrente demonstram o incremento da situação financeira do período de 2006 até 2009 (aumentou de 0,91 para 1,19). Apresentou queda da liquidez corrente em $2010(1,0)$, mas com resultado superior ao período inicial de 2006 e recuperação no período de 2011 a 2013 (1,10; 1,02 e 1,15 respectivamente).

Ao avaliarem a saúde financeira dos municípios da região sul do Brasil, MACEDO et al. (2012) identificaram que a crise sub-prime de 2007 não impactou nos índices de liquidez desses municípios. No caso do Estado de Goiás, a crise subprime de 2007 também não afetou a liquidez, a qual apresentou uma variação crescente ao longo do período analisado (2006 a 2013), com exceção do ano de 2010.

Na Figura 1-B é possível notar que a partir do exercício de 2008, o Ativo Financeiro sempre superou o Passivo Financeiro, ou seja, a disponibilidade financeira demonstrou-se suficiente para o pagamento das dívidas de curto prazo. Ademais, no período de 2008 a 2013 a liquidez corrente mostrou-se superior a 1 (Figura 1-A), ou seja, os recursos financeiros são suficientes para pagar as dívidas de curto prazo.

Diga-se ainda, que em 2013, apesar de apresentar crescimento líquido positivo, os resultados apresentados não superam a melhor situação financeira evidenciada ao final do exercício de 2009. Uma situação curiosa revela-se no exercício de 2010, no qual foi apresentado um dos piores índices financeiros, coincidente com o fim de mandato de um período de gestão do governo do Estado.

Segundo SOUZA (2013), há uma maior probabilidade de ocorrência de insuficiência de caixa no ano eleitoral, porque têm-se a expectativa de reeleição, mas ao mesmo tempo a possibilidade de alternância de governo em caso de derrota. Para o autor, os governantes diante da percepção do risco de alternância de governo procuram transferir as dívidas da gestão para o possível sucessor, havendo, portanto, uma relação positiva e direta entre o risco de alternância de governo e a insuficiência de caixa. Diante dessas explicações, justifica-se a redução de caixa no ano de 2010, pois corresponde ao período eleitoral, sendo interpretado como um fator de risco para recondução da gestão.

No que se refere a liquidez imediata, tendo por base a Tabela 1, verifica-se que a disponibilidade imediata ou de alta liquidez (Ativo Disponível) apresentou crescimento monetário no decorrer do período de análise, a exceção do exercício de 2010, no qual apresentou queda, chegando ao seu patamar máximo em 2013, 
quando somou uma quantia de cerca de 3,3 bilhões de reais.

Por outro lado, de acordo com o que revela a Figura 1-A, somente a partir do exercício de 2013 o governo do Estado de Goiás passou a apresentar recursos financeiros disponíveis suficientes para liquidar a totalidade de obrigações de curto prazo que compõe o passivo financeiro (A.Disp. > 1). Em 2013, para cada $R \$ 1,00$ de dívida registrada no passivo financeiro, possui $R \$ 1,08$ em espécie ou direitos de alta liquidez para o pagamento. Entretanto, no restante da série histórica, ou seja, de 2006 a 2012 as obrigações de curto prazo superaram a disponibilidade financeira (A.Disp. <1). Na Tabela 2 é evidenciado o comportamento da Receita Corrente Líquida nos exercícios de 2006 a 2013:

TABELA 2 - Evolução da Receita Corrente Líquida do Estado de Goiás

\begin{tabular}{c|cc|c|c}
\hline Ano & \multicolumn{1}{c|}{$\mathrm{RCL}$} & $\mathrm{AH} R \mathrm{RCL}$ Base Ano Anterior & $\mathrm{AH}$ RCL Base Ano 2006 \\
\hline 2006 & $\mathrm{R} \$$ & $6.644 .126 .000,00$ & - & $100,00 \%$ \\
2007 & $\mathrm{R} \$$ & $7.161 .427 .000,00$ & $107,79 \%$ & $107,79 \%$ \\
2008 & $\mathrm{R} \$$ & $8.517 .838 .000,00$ & $118,94 \%$ & $128,20 \%$ \\
2009 & $\mathrm{R} \$$ & $8.693 .964 .490,67$ & $102,07 \%$ & $130,85 \%$ \\
2010 & $\mathrm{R} \$$ & $10.047 .292 .664,45$ & $115,57 \%$ & $151,22 \%$ \\
2011 & $\mathrm{R} \$$ & $12.064 .841 .153,42$ & $120,08 \%$ & $181,59 \%$ \\
2012 & $\mathrm{R} \$$ & $13.365 .786 .266,00$ & $110,78 \%$ & $201,17 \%$ \\
2013 & $\mathrm{R} \$$ & $14.413 .466 .418,78$ & $107,84 \%$ & $216,94 \%$ \\
\hline
\end{tabular}

RCL: Receita Corrente Líquida

AH RCL: Análise Horizontal da Receita Corrente Líquida

Fonte: Goiás, RREO - Relatório Resumido da Execução Orçamentária (Anos 2006, 2007, 2008, 2009, 2010, 2011, 2012, 2013).

No período entre 2006 a 2013 a Receita Corrente Líquida (RCL) apresentou um acréscimo de $R \$ 7.769 .340 .418,78$ representando um aumento de $116,94 \%$ da $R C L$ de 2006 em relação a 2013. Percebe-se ainda, que a variação da RCL ao longo dos exercícios não apresentou crescimento uniforme, havendo bastante disparidade: nos oito exercícios analisados, 2009 foi o exercício que apresentou o menor crescimento em relação ao exercício anterior aumentando apenas 2,07\% em relação a 2008.

Ao analisarem o comportamento das despesas correntes do Estado da Paraíba no período de 2008 a 2011, PEREIRA \& JACINTO (2016) evidenciaram resultados semelhantes aos encontrados neste estudo, no que se refere ao comportamento da Receita Corrente Líquida. De acordo com os dados dos autores, a RCL cresceu 36,46\%, de 2008 a 2011. Por sua vez, no Estado de Goiás a RCL cresceu 41,64\% no período de 2008 a 2011, o que demonstra um crescimento no âmbito dos dois Estados, mas Goiás com um desempenho um pouco superior a Paraíba.

JUNIOR (2015), que pesquisou as finanças do Estado do Rio Grande do Sul de 2010 a 2014, evidenciou que a RCL cresceu apenas $30 \%$ no período. Comparativamente, da análise dos dados de Goiás, verifica-se que o crescimento da RCL foi da ordem de 43,45\% no período de 2010 a 2014, o que demonstra um desempenho superior em termos percentuais, em relação ao Estado do Rio Grande do Sul.

De acordo com SILVA et al. (2013), em razão do desaquecimento da economia, o governo brasileiro promoveu a redução da carga tributária de alguns produtos, os quais tiveram sua demanda afetada pela crise, e, como consequência, houve uma sensível diminuição das receitas inicialmente previstas para o ano de 2009. Por outro lado, em 2011 a Receita Corrente Líquida aumentou 20,08\% em 
relação a 2010, apresentando o maior crescimento percentual do período analisado.

Em relação ao endividamento, a evolução da dívida flutuante do Estado de Goiás foi analisada no período de 2006 a 2013. Há de se dizer que a dívida flutuante corresponde aos compromissos assumidos pelo ente público e que tem prazo de vencimento inferior a 12 meses. Na Tabela 3 são evidenciados os saldos anteriores da dívida flutuante, ou seja, em 31 de dezembro de exercício anterior ao de referência e o montante da despesa realizada no exercício:

TABELA 3 - Evolução da Dívida Flutuante do Estado de Goiás

\begin{tabular}{c|c|c|c}
\hline \multirow{2}{*}{ Ano } & Saldo da Dívida em 31/12 & $\begin{array}{c}\text { Despesa Orçamentária } \\
\text { Incorrida }\end{array}$ & $\begin{array}{c}\text { Representatividade do } \\
\text { Saldo da Dívida }\end{array}$ \\
\cline { 2 - 4 } & $\mathrm{A}$ & $\mathrm{B}$ & $\mathrm{C}=(\mathrm{A} / \mathrm{B}) \times 100$ \\
\hline 2006 & $\mathrm{R} \$ 2.020 .647 .692,84$ & $\mathrm{R} \$ 8.294 .233 .741,69$ & $24,36 \%$ \\
2007 & $\mathrm{R} \$ 2.441 .391 .656,85$ & $\mathrm{R} \$ 9.541 .031 .733,48$ & $25,59 \%$ \\
2008 & $\mathrm{R} \$ 2.427 .908 .746,99$ & $\mathrm{R} \$ 11.068 .637 .198,92$ & $21,94 \%$ \\
2009 & $\mathrm{R} \$ 2.341 .873 .381,06$ & $\mathrm{R} \$ 11.805 .556 .739,46$ & $19,84 \%$ \\
2010 & $\mathrm{R} \$ 2.436 .886 .004,40$ & $\mathrm{R} \$ 14.566 .715 .600,32$ & $16,73 \%$ \\
2011 & $\mathrm{R} \$ 2.733 .798 .429,99$ & $\mathrm{R} \$ 14.703 .479 .396,53$ & $18,59 \%$ \\
2012 & $\mathrm{R} \$ 3.306 .729 .094,49$ & $\mathrm{R} \$ 17.441 .751 .026,13$ & $18,96 \%$ \\
2013 & $\mathrm{R} \$ 3.068 .673 .025,98$ & $\mathrm{R} \$ 18.606 .248 .083,17$ & $16,49 \%$ \\
\hline
\end{tabular}

Fonte: Goiás, Saldo da Dívida em 31/12: Demonstração da Dívida Flutuante e Balanço Patrimonial (Anos 2006, 2007, 2008, 2009, 2010, 2011, 2012, 2013); Despesa Orçamentária Realizada: Comparativo da Despesa Orçada, Autorizada e Realizada Segundo as Categorias Econômicas e Elementos de Despesa (Anos 2006, 2007, 2008, 2009, 2010, 2011, 2012, 2013).

Com base no Quadro 2, elaborou-se os gráficos representados pela Figura 2, que demonstram a evolução monetária do saldo da dívida flutuante em comparação com a despesa realizada (Figura 2-A) e também a comparação do percentual do saldo da dívida flutuante em relação ao montante da despesa realizada (Figura 2-B). Esclarece-se que a despesa realizada corresponde ao total de despesas orçamentárias empenhadas nas categorias econômicas correntes e de capital, em cada exercício.

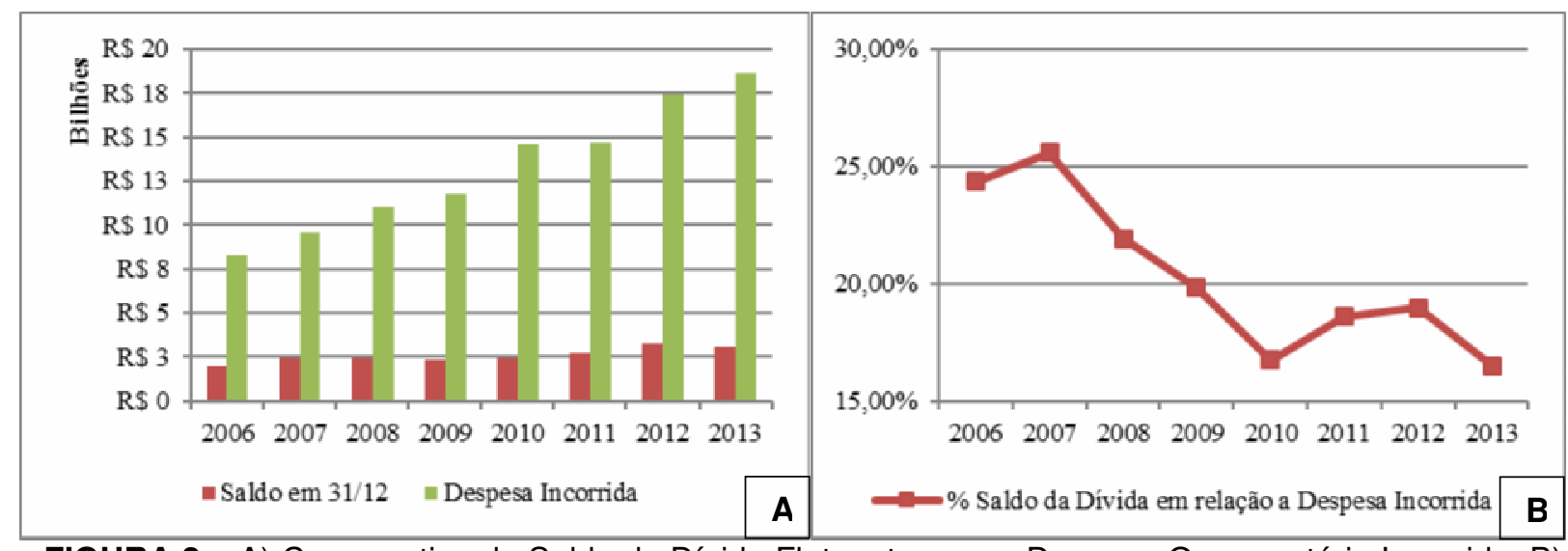

FIGURA 2 - A) Comparativo do Saldo da Dívida Flutuante com a Despesa Orçamentária Incorrida; B) Evolução percentual do Saldo da Dívida Flutuante em relação a Despesa Orçamentária Incorrida (corrente e capital)

Fonte: Goiás, Saldo da Dívida Flutuante: Balanço Patrimonial e Demonstrativo da Dívida Flutuante; Despesa Incorrida: Comparativo da Despesa Orçada, Autorizada e Realizada Segundo as Categorias Econômicas e Elementos de Despesa - Anexo 02 Lei 4320/64; (Anos 2006, 2007, 2008, 2009, 2010, 2011, 2012, 2013).

Da análise da Figura 2, verificou-se que, apesar do aumento da despesa orçamentária incorrida ao longo dos anos, o saldo da dívida flutuante permaneceu 
levemente estável, com pequeno indicativo de aumento, em termos monetários. Isso significa que o Estado está gastando mais, porém está conseguindo adimplir a maior parte dessas obrigações de curto prazo dentro do próprio exercício financeiro, deixando uma menor proporção de gasto para ser adimplido no exercício subsequente. Note-se que a despesa incorrida mais que dobrou em 2006 comparada a 2013, passando de 8 bilhões em 2006 para 18 bilhões em 2013, refletindo o crescimento do orçamento público do Estado de Goiás no decorrer desses anos.

Por sua vez, ao analisar o comportamento do saldo da dívida flutuante podese verificar a tendência de queda do percentual da dívida em relação ao montante das despesas incorridas. Por exemplo, em 2006 o saldo da dívida flutuante representava pouco menos de $25 \%$ da despesa realizada no exercício; aumentando o percentual no exercício de 2007, momento em que atingiu seu pico, chegando à marca de 25,59\%. A partir de então, o percentual passa a entrar em queda livre nos anos subsequentes até 2010, quanto atinge o patamar de 16,73\%. Nos anos de 2011 e 2012 esse percentual volta a manter uma tendência de crescimento atingindo o patamar de $18,96 \%$ em 2012. Volta a cair em 2013, quando atinge o percentual mínimo da série histórica, correspondendo a 16,49\% da despesa total incorrida.

A dívida fundada que é composta pelas obrigações de longo prazo contraídas com vencimento superior a 12 meses. É composta pela dívida interna e pela externa. No Estado de Goiás, mais de 99\% do montante da dívida pública fundada possui como credoras instituições de ordem interna. No que se refere à dívida externa é traduzida em moeda corrente de acordo com a cotação da moeda americana em 31 de dezembro de cada ano, se considerado o Balanço Geral. A Tabela 4 evidencia a evolução monetária da dívida fundada do Estado de Goiás nos anos de 2006 a 2013:

TABELA 4 - Evolução da Dívida Consolidada do Estado de Goiás (R\$1,00)

\begin{tabular}{c|c|c|c}
\hline Ano & $\begin{array}{c}\text { Dívida Pública Fundada - } \\
\text { Interna (Saldo) }\end{array}$ & $\begin{array}{c}\text { Dívida Pública Fundada - } \\
\text { Externa (Saldo) }\end{array}$ & $\begin{array}{c}\text { Dívida Consolidada } \\
\text { (Externa + Interna) }\end{array}$ \\
\hline 2006 & $12.284 .387 .921,00$ & $143.858 .123,00$ & $12.428 .246 .044,00$ \\
2007 & $12.524 .317 .286,00$ & $113.170 .654,00$ & $12.637 .487 .940,00$ \\
2008 & $13.168 .024 .255,00$ & $129.207 .778,00$ & $13.297 .232 .033,00$ \\
2009 & $12.533 .831 .644,00$ & $83.723 .946,00$ & $12.617 .555 .590,00$ \\
2010 & $14.698 .902 .997,00$ & $67.796 .144,00$ & $14.766 .699 .141,00$ \\
2011 & $15.140 .044 .549,00$ & $62.679 .282,00$ & $15.202 .723 .831,00$ \\
2012 & $16.172 .294 .031,00$ & $53.457 .622,00$ & $16.225 .751 .653,00$ \\
2013 & $16.718 .111 .242,00$ & $45.244 .286,00$ & $16.763 .355 .528,00$ \\
\hline
\end{tabular}

Fonte: Goiás, Balanço Patrimonial (Anos 2006, 2007, 2008, 2009, 2010, 2011, 2012, 2013); Demonstrativo da Dívida Consolidada (Anos 2006, 2007, 2008, 2009, 2010, 2011, 2012, 2013).

A dívida pública interna demonstrou crescimento ao longo do período de análise, ao contrário da dívida pública externa que vem caindo continuamente desde 2006. Esse cenário de crescimento do endividamento não é apenas local. CUNHA \& GARCIA (2012), ao analisarem o gerenciamento do endividamento público brasileiro, identificaram que os incentivos parafiscais concedidos entre 2009 e 2010 comprometeram significantemente o orçamento fiscal e, com isso, contribuíram para o aumento da dívida bruta.

Como já dito anteriormente, a dívida do Estado de Goiás concentra-se internamente. É possível ainda vislumbrar, em especial o ano de 2010, quando houve um incremento considerável do endividamento de longo prazo, de forma que 
a dívida fundada interna cresceu $17,27 \%$ neste ano em comparação ao anterior. Os valores monetários da dívida pública fundada interna e externa podem ainda ser traduzidos dessa forma (Figura 3):

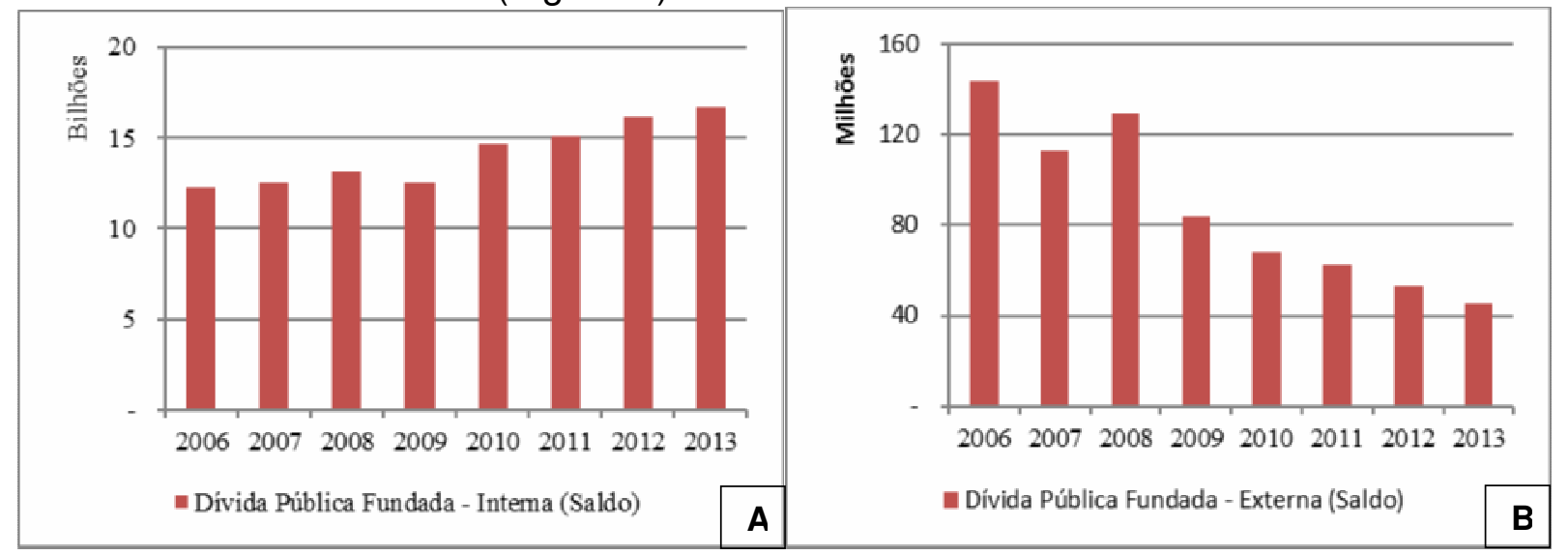

FIGURA 3 - A) Dívida Fundada Interna; B) Dívida Fundada Externa.

Fonte: Goiás, Balanço Patrimonial e Demonstrativo da Dívida Consolidada Líquida - Anexo II do Relatório de Gestão Fiscal (Anos 2006, 2007, 2008, 2009, 2010, 2011, 2012, 2013).

A Figura 3 evidencia o crescimento da dívida fundada interna e o decréscimo da dívida fundada externa do Estado de Goiás. O crescimento da dívida interna do Estado de Goiás aumentou sensivelmente a partir do ano de 2010 e corrobora com SOARES et al. (2013), que identificaram um crescimento da média da dívida pública estadual neste mesmo ano de 2010, ao estudarem o comportamento do endividamento dos estados brasileiros. Entretanto, os autores encontraram um aumento da dívida dos Estados para o ano de 2009, o que contraria o resultado encontrado para o Estado de Goiás, que apresentou uma diminuição da dívida pública interna no ano de 2009.

De acordo com SUZART (2013), o endividamento da União influencia diretamente o crescimento das dívidas estaduais, mas não induz ao aumento das dívidas municipais. Por outro lado, segundo o autor, o endividamento estadual induz ao aumento da dívida municipal, porém, a associação não tem qualquer relação de dependência entre os governos subnacionais com a União. Diante do exposto, sugere-se que o crescimento da Dívida Pública Fundada Interna do Estado de Goiás poderia estar sofrendo fortes influências do endividamento do governo federal.

\section{CONCLUSÕES}

A saúde financeira do Estado de Goiás no ano de 2013 está em sua melhor condição se comparada aos anos anteriores da série histórica, que iniciou em 2006.

Um dos piores índices financeiros verificados foi verificado em 2010 e coincide com o período eleitoral para o governo do Estado.

A Dívida Consolidada, que corresponde as obrigações de longo prazo está aumentando ao longo dos últimos anos.

\section{REFERÊNCIAS}

ANDRADE, N. A. Contabilidade pública na gestão municipal. 5. ed. São Paulo: Atlas, 2013.

BRASIL. Lei no 4.320, de 17 de março de 1964. Estatui Normas Gerais de Direito Financeiro para elaboração e controle dos orçamentos e balanços da União, dos Estados, dos Municípios e do Distrito Federal. Disponível em: < 
http://www.planalto.gov.br/ccivil_03/leis/44320.htm>. Acesso em 02 fev. 2015.

. Lei Complementar no 101, de 4 de maio de 2000. Estabelece normas de finanças públicas voltadas para a responsabilidade na gestão fiscal e dá outras providências.

Disponível

em:

<http://www.planalto.gov.br/ccivil_03/leis/lcp/lcp101.htm>. Acesso em: 07 fev. 2015.

CERVO, A. L. Metodologia científica. 6. ed. São Paulo: Pearson Prentice Hall, 2007.

COELHO, D. M.; QUINTANA, A. C. Análise do desempenho econômico e financeiro de entidades da administração pública direta: O caso da Prefeitura Municipal do Rio Grande (RS). Revista de Contabilidade do Mestrado em Ciências Contábeis da UERJ, v. 13, n. 2, p. 1-15, 2008. Disponível em: <http://www.epublicacoes.uerj.br/index.php/rcmccuerj/article/view/5552>. Acesso em 02 fev. 2015.

CUNHA, P. M. DA; GARCIA, M. G. P. A gerência recente do endividamento público brasileiro. Revista de Economia Política, v. 32, n. 2, p. 260-281, 2012. Disponível em: < http://www.scielo.br/scielo.php?script=sci_arttext\&pid=S010131572012000200007>. Acesso em 06 mar. 2015.

GOIÁS. Balanço Geral do Estado de Goiás - 2006 a 2013. Disponível em: < http://www.sefaz.go.gov.br>. Acesso em 28 jan. 2015.

Relatórios da Lei de Responsabilidade Fiscal - 2006 a 2013. Disponível em: < http://www.transparencia.go.gov.br/>. Acesso em 28 jan. 2015.

Portal

Transparência.

Disponível

em:

$\overline{<h t t p: / / w w w . t r a n s p a r e n c i a . g o . g o v . b r / p a g i n a . p h p ? i d=18>. ~ A c e s s o ~ e m ~} 01$ ago. 2015.

JUNIOR, L. DOS S. M. A consolidação fiscal do Estado do Rio Grande do Sul é necessária? Indicadores Econômicos FEE, v. 42, n. 4, p. 85-98, 2015. Disponível em: <http://revistas.fee.tche.br/index.php/indicadores/article/view/3495>. Acesso em 5 mar. 2017.

MACÊDO, F. F. R. R.; VESCO, D. G. D.; FILHO, J. R. D. T. Liquidez e endividamento dos municípios da região sul do Brasil. BASE - Revista de Administração e Contabilidade da Unisinos, v. 9, n. 4, p. 329-339, 2012. Disponível em: <http://revistas.unisinos.br/index.php/base/article/viewFile/base.2012.94.02/1264>. Acesso em 4 mar. 2017.

PEREIRA, V.; JACINTO, L. Análise das despesas públicas correntes no âmbito do governo do Estado da Paraíba. Revista de Contabilidade da UFBA, v. 10, n. 2, p. $26-42$ 2016.

Disponível

em:

<https://portalseer.ufba.br/index.php/rcontabilidade/article/view/15023>. Acesso em 5 mar. 2017.

SILVA, A. A. Estrutura, análise e interpretação das demonstrações contábeis. 4. ed. São Paulo: Atlas: 2014. 
SILVA, M. C.; TAVARES, A. L.; ARAUJO, A. O.; SILVA, J. D. G. Análises de Balanços Públicos: Quociente do Resultado Orçamentário do Governo Federal. 2000 - 2009. Contabilidade Vista \& Revista, v. 24, n. 3, p. 15-34, 2013. Disponível em: $<$ http://revistas.face.ufmg.br/index.php/contabilidadevistaerevista/article/view/1271>. Acesso em 25 fev. 2015.

SOARES, C. S.; CERETTA, P. S.; CORONEL, D. A.; VIEIRA, K. M. A Lei de Responsabilidade Fiscal e o Comportamento do Endividamento dos Estados Brasileiros $\square$ : uma análise de dados em painel de 2000 a 2010. Revista ADMpg Gestão Estratégica, v. 6, n. 1, p. 79-87, 2013. Disponível em: <http://www.admpg.com.br/revista2013_1/artigo.html>. Acesso em: 6 mar. 2017.

SOARES, M.; LYRA, R. L. W. C. DE; HEIN, N.; KROENKE, A. O emprego da análise de balanços e métodos estatísticos na área pública: o ranking de gestão dos municípios catarinenses. Revista de Administração Pública, v. 45, n. 5, p. 14251443 2011.

Disponível em: http://www.scielo.br/scielo.php?script=sci_arttext\&pid=S0034-76122011000500008>. Acesso em 6 mar. 2017.

SOUZA, S. De regras, austeridade e oportunismo: notas modernas sobre um antigo dilema. Cadernos de Estudos Sociais e Políticos, v. 2, n. 3, p. 130-159, 2013. Disponível em: $<$ http://www.epublicacoes.uerj.br/index.php/CESP/article/view/18983>. Acesso em 4 mar. 2017.

SUZART, J. A. DA S. Dívida dos Governos Subnacionais Brasileiros: Uma Análise sob a Ótica do Federalismo Fiscal. Administração Pública e Gestão Social, v. 5, n. 2, p. 44-53, 2013. Disponível em: <http://www.apgs.ufv.br/index.php/apgs/article/view/481\#>. Acesso em 5 mar. 2017. 